\title{
Dual Roles of Endogenous Platelet-Activating Factor Acetylhydrolase in a Murine Model of Necrotizing Enterocolitis
}

\author{
JING LU, MARISSA PIERCE, ANDREW FRANKLIN, TAMAS JILLING, DIANA M. STAFFORINI, AND MICHAEL CAPLAN
}

Department of Pediatrics [J.L., M.P., A.F., T.J., M.C.], Pritzker School of Medicine, University of Chicago, Evanston, Illinois 60201; Department of Internal Medicine [D.M.S.], Huntsman Cancer Institute, University of Utah, Salt Lake City, Utah 84112

\begin{abstract}
Human preterm infants with necrotizing enterocolitis (NEC) have increased circulating and luminal levels of plateletactivating factor (PAF) and decreased serum PAF-acetylhydrolase (PAF-AH), the enzyme that inactivates PAF. Formula supplemented with recombinant PAF-AH decreases NEC in a neonatal rat model. We hypothesized that endogenous PAF-AH contributes to neonatal intestinal homeostasis and therefore developed $\mathrm{PAF}-\mathrm{AH}^{-1-}$ mice using standard approaches to study the role of this enzyme in the neonatal NEC model. After exposure to a well-established NEC model, intestinal tissues were evaluated for histology, proinflammatory cytokine mRNA synthesis, and death using standard techniques. We found that mortality rates were significantly lower in PAF$\mathrm{AH}^{-/-}$pups compared with wild-type controls before $24 \mathrm{~h}$ of life but surviving PAF-AH ${ }^{-1-}$ animals were more susceptible to NEC development compared with wild-type controls. Increased NEC incidence was associated with prominent inflammation characterized by elevated intestinal mRNA expression of $\mathrm{sPA}_{2}$, inducible NOS, and CXCL1. In conclusion, the data support a protective role for endogenous PAF-AH in the development of NEC, and because preterm neonates have endogenous PAF-AH deficiency, this may place them at increased risk for disease. (Pediatr Res 68: 225-230, 2010)
\end{abstract}

$\mathrm{N}^{\mathrm{en}}$ eonatal necrotizing enterocolitis (NEC) is a common and devastating condition that afflicts premature newborn infants and is characterized by acute onset of intestinal inflammatory necrosis. The cause of NEC has not been elucidated, and mortality rates remain unacceptably high (1). Prematurity, formula feeding, intestinal ischemia, and bacterial colonization may contribute to the pathogenesis of NEC, because these stresses initiate proinflammatory signaling and intestinal injury in susceptible hosts. Platelet-activating factor (PAF, 1-O-alkyl-2-acetyl-sn-glycero-3-phosphocholine) is a potent proinflammatory mediator that contributes to the pathogenesis of NEC (2,3). PAF initiates signaling after binding to a G-protein-coupled receptor [PAF receptor, PAFR (4)] and activation of downstream events that result in epithelial apoptosis, leukocyte activation, and the initiation of NEC in experimental systems (5-7). Studies in human infants with NEC revealed increased luminal and systemic accumulation of PAF and decreased expression of PAF acetylhydrolase [PAF-AH, also known as PLA $\mathrm{PL}_{2}$, LpPLA $\left.2(8,9)\right]$. PAF-AH catalyzes the hydrolysis of the acetyl group esterifying the

Received March 10, 2010; accepted May 17, 2010.

Correspondence: Michael S. Caplan, M.D., Northshore University Healthsystem, 2650 Ridge Avenue, Evanston, IL 60201; e-mail: mcaplan@northshore.org

Supported by NIH grants HD37581 and AI058128 [M.S.C. and T.J.] and HL35828 [D.M.S.]. $s n-2$ position of PAF, thereby abolishing its biologic activity (10). PAF-AHs exist in secreted (11) and intracellular (12) forms. The secreted form is found in biologic fluids, including plasma (11) and breast milk (13), but is absent in infant formula. Human neonates are deficient in PAF-AH expression and enteral administration of the recombinant enzyme markedly reduced the incidence of NEC in a rat model of the disease (14). To assess the importance of endogenous PAF-AH activity in neonatal NEC, intestinal inflammatory responses, and survival, we developed genetically engineered mice that lack expression of the plasma form of this enzyme. We found that deletion of PAF-AH reduced early mortality associated with bacterial exposure and asphyxia, but that survivors had significantly higher incidence of NEC and increased expression of proinflammatory mediators compared with wild-type mice. These findings suggest that endogenous PAF-AH protects against NEC and that deficiency of this protein, a feature characteristic of preterm infants, increases the risk of developing this disease.

\section{METHODS}

Animal model of NEC. All animal protocols were reviewed and approved by the NorthShore University Health System Institutional Animal Care and Use Committee. To investigate the impact of PAF-AH in neonatal NEC, we used a previously described rodent model of the disease $(15,16)$. Neonatal mice were obtained from timed-pregnant animals via cesarean section at postconception days E20-21. Wild-type controls were C57BL/6J and the PAF-AH knockouts were backcrossed eight times onto the C57BL/6J parental strain before initiating experiments. Neonatal pups were gavaged using a $1.9 \mathrm{~F}$ silicone catheter (PICC-NATE, UT Medical Products) containing Esbilac formula (PetAg, Inc.; $1.8 \mathrm{kcal} / \mathrm{mL}$ ) every $3 \mathrm{~h}$ and supplemented with $1 \times 10^{7}$ or $1 \times 10^{4}$ bacterial loads of Serratia marcescens and Streptococcus viridans in their first feeding after birth and on each succeeding day. Pups were exposed to a brief episode of asphyxia $\left(60 \mathrm{~s}\right.$ in $100 \% \mathrm{~N}_{2}$ ) followed by cold stress $\left(4^{\circ} \mathrm{C}\right.$ for $\left.10 \mathrm{~min}\right)$ twice daily. Neonatal mice were monitored for $\sim 24-48 \mathrm{~h}$, a time during which NEC is known to develop. The pups were euthanized when signs of distress were apparent, or at $24-48 \mathrm{~h}$, depending on the experimental design. We then isolated intestinal sections for histologic analyses. Portions of the tissues were snap-frozen in liquid $\mathrm{N}_{2}$ and kept at $-80^{\circ} \mathrm{C}$ for RNA extraction.

Histology. The intestine was removed and linearized in ice-cold normal saline solution. Duodenum, jejunum, ileum, and colon were embedded in OCT, sectioned, and stained with hematoxylin and eosin (H\&E). A score was assigned by a blinded reviewer, using the NEC scoring system that we published previously (17). Briefly, intact villi received a score of 0 , sloughing of epithelial cells on villous tips was scored 1 , mid-villous damage was scored

\footnotetext{
Abbreviations: GAPDH, glyceraldehyde-3-phosphate dehydrogenase; NEC, necrotizing enterocolitis; PAFR, platelet-activating factor receptor; PAF-AH, PAF-acetylhydrolase; PLA 2 , phospholipase $\mathrm{A}_{2}$
} 
2, a score of 3 represented complete villous necrosis, and 4 indicated transmural necrosis. Scores $\geq 2$ were considered indicative of NEC.

$\boldsymbol{P A F}-\boldsymbol{A H}$ activity assays. Intestinal PAF-AH activity was assayed according to Narahara et al. (18) and Miwa et al. (19), with minor modifications. Intestinal lysates were diluted to a concentration of $0.5 \mathrm{mg} / \mathrm{mL}$ using $0.25 \mathrm{M}$ sucrose, before the assays. The mixtures included $50 \mu \mathrm{L}$ of diluted samples, $300 \mu \mathrm{L}$ of $50 \mathrm{mM}$ Tris- $\mathrm{HCl}(\mathrm{pH} 7.5$ ) containing $0.2 \% \mathrm{BSA}, 25 \mathrm{nmol}$ of cold PAF, and $1 \mu \mathrm{L}$ of 1-O-hexadecyl-2-[ $\left[{ }^{3} \mathrm{H}\right.$-acetyl] PAF $(0.1 \mathrm{mCi} / \mathrm{mL}$, PerkinElmer Life and Analytical Sciences, Inc., Boston, MA) in fatty acid-free BSA ( $0.2 \%$ final concentration). The volume was adjusted to $0.5 \mathrm{~mL}$, and the reactions were terminated after $20 \mathrm{~min}$ with trichloroacetic acid (14\%). One-tenth of the supernatant was added to $5 \mathrm{~mL}$ of scintillation fluid (Perkin-Elmer Life and Analytical Sciences), and the released $\left[{ }^{3} \mathrm{H}\right]$-acetate was quantified by scintillation counting. Plasma PAF-AH activity was determined as previously described (20).

Quantitative RT-PCR. RNA samples were extracted from the ileum using RNeasy mini kits and Qiacube (Qiagen), following instructions provided by the manufacturer. RNA concentrations were measured by staining using SYBR Green II (Molecular Probes, Inc.). Blanks, standards, and samples were stained in DNAse and RNAse-free TE buffer (1:10,000-fold dilution). We determined the fluorescence intensity of RNA/SYBR Green II complexes and then calculated RNA concentrations based on a standard curve. Each PCR reaction (total volume $=10 \mu \mathrm{L}$ ) contained $0.5 \mu \mathrm{L}$ of cDNA, $0.5 \mu \mathrm{L}$ of glyceraldehyde-3-phosphate dehydrogenase (GAPDH) primers (final concentration $=0.5 \mu \mathrm{M}$ ), $0.5 \mu \mathrm{L}$ of primer mix of gene of interest (final concentration $=0.5 \mu \mathrm{M}$ ), $5 \mu \mathrm{L}$ of PerfeCTa qPCR SuperMix, UNG (Quanta BioSciences, Inc.), and $3.5 \mu \mathrm{L}$ of DNAse-free, RNAse-free water. Reactions used cycling conditions that were optimized for these experiments. mRNA levels are expressed relative to those of GAPDH. The sequences of the primers used were previously described $(16,21)$.

Statistics. Parametric data are presented as mean \pm SEM. Comparisons between two groups were carried out using $t$ test for unpaired data. Comparisons between three or more groups were performed using ANOVA and differences between groups were assessed using Tukey's post hoc test. Analysis of two independent variables was performed with a two-way ANOVA test. Ordinate data to compare mortality rates and NEC incidence rates were analyzed using a $\chi^{2}$ test. Unless otherwise stated, a $p$ value $<0.05$ was considered significant,

\section{RESULTS}

Targeted disruption of the mouse PAF-AH gene. A $15.3-\mathrm{kb}$ clone isolated from an adult $129 / \mathrm{SvJ}$ genomic DNA library spanned exons $2-7$ of the mouse PAF-AH gene and was used to generate a targeting vector in which exons 3 and 4 were replaced by a self-excision cassette, ACN (22) (Fig. $1 A)$. The resulting DNA (PAF-AH ${ }^{\mathrm{ACN}}$ ) was cloned into a plasmid that contained two copies of the TK gene in pBluescript, to generate a targeting vector. Screening was performed by long-range PCR using a primer located 218-bp upstream of the region of homology (p1, Fig. 1B) combined with control (p2) and diagnostic (p3) primers (Fig. 1B). A positive ES clone was microinjected into 126 blastocysts at Xenogen, and a chimeric male $(\chi)$ was bred to C57BL/6J females. Genomic DNA samples from positive and negative ES cells, from a chimeric mouse $(\chi)$, and from positive and negative $F_{1}$ progeny were analyzed in three independent PCR reactions (Fig. $1 C$ ). The mRNA generated in PAF-AH ${ }^{-1-}$ animals lacked exons 3 and 4, as expected (not shown). We determined the levels of PAF-AH activity in the plasma of wild-type and PAF-AH ${ }^{-1-}$ adult mice. The expression levels were consistent with our predictions based on genetic analyses (Fig. 1D). PAF-AH-deficient mice were generated at the University of Utah under the direction of DMS.

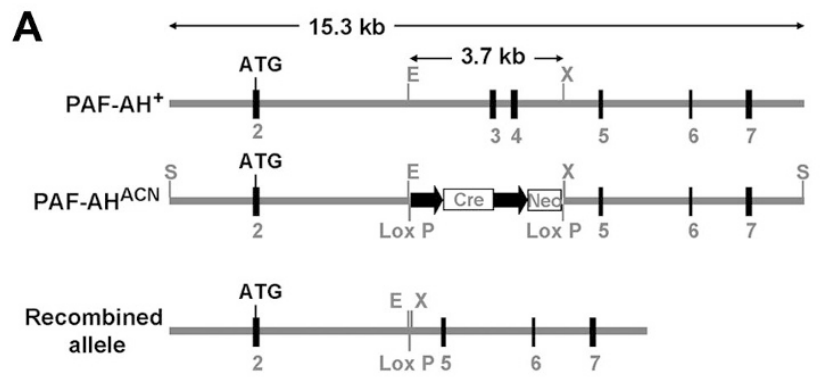

\section{B}
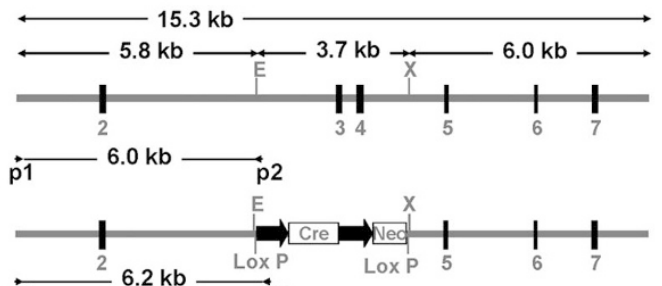

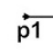

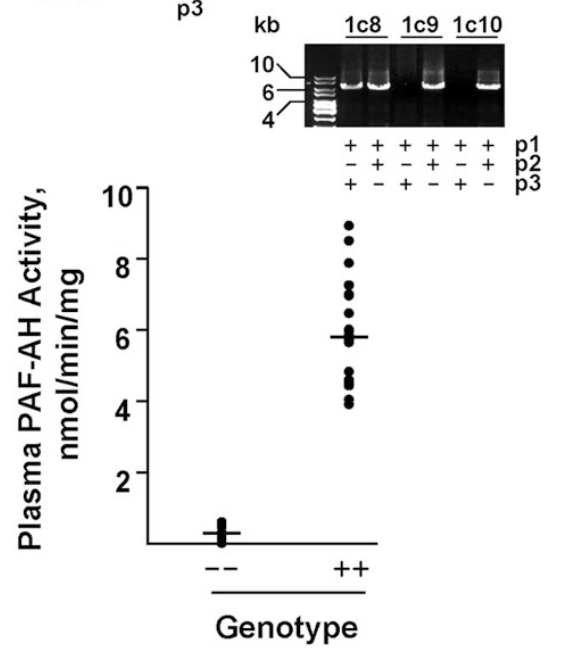

C

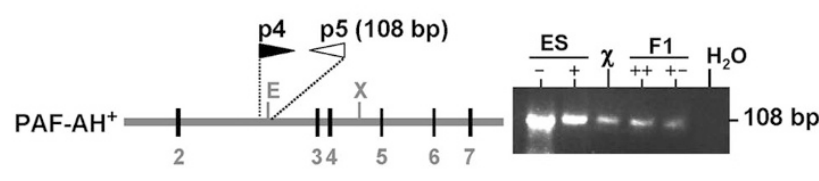

D

Figure 1. Targeted disruption of the mouse PAF-AH gene. (A) Mouse PAF-AH genomic locus and targeting strategy. E, EcoRI site; P, loxP site; S, SalI site; $\mathrm{X}, \mathrm{XhoI}$ site. $(B)$ Long-range PCR analysis used to detect correct targeting in ES cell clones. Each clone was evaluated using control PCR primers (p1 and p2) and diagnostic primers (p1 and p3). The bottom panel shows examples of positive (1c8) and negative (1c9, 1c10) ES clones. (C) Germline transmission of the targeted allele to the $\mathrm{F}_{1}$ generation was determined by PCR using a variety of primer combinations. The right panels show analyses of wild-type ( - ) and targeted $(+)$ ES cell DNA, tail DNA from a chimeric mouse $(\chi)$, and DNA from $\mathrm{F}^{+/+}$and $\mathrm{F} 1^{-1+}$ mice. $(D)$ Levels of serum PAF-AH activity in wild-type $(n=20)$ and PAF-AH deficient mice $(n=14)$. 

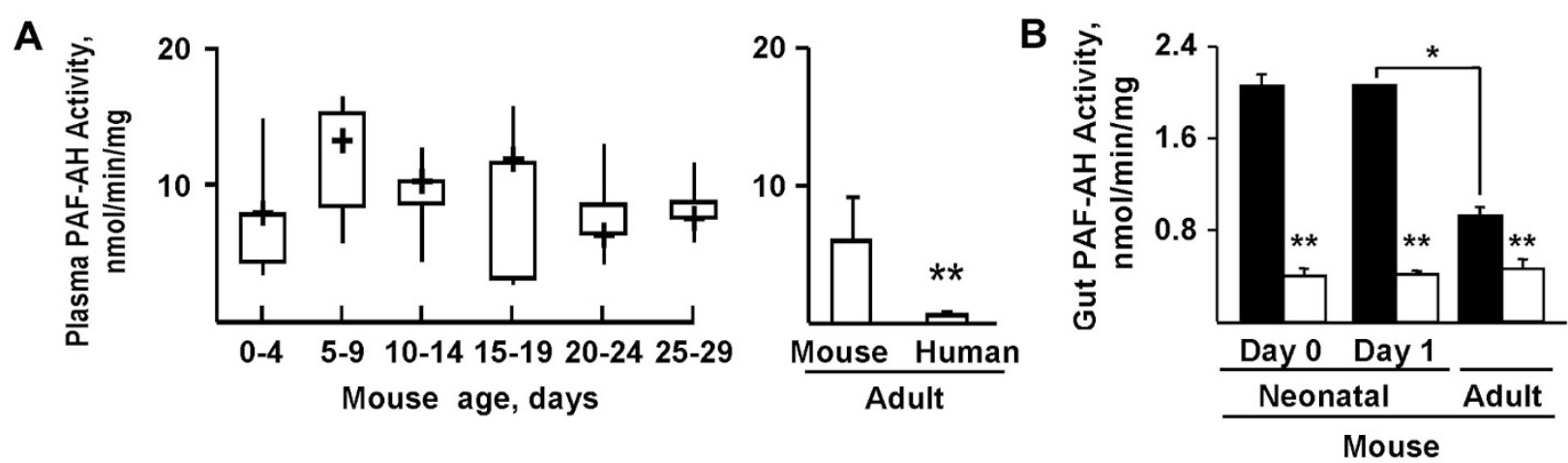

Figure 2. PAF-AH activity in plasma and intestinal tissues of wild-type and $\mathrm{PAF}-\mathrm{AH}^{-1-}$ mice. PAF-AH activity was determined as the rate of $\left[{ }^{3} \mathrm{H}\right]$ acetate released from 1-O-hexadecyl-[ ${ }^{3} \mathrm{H}$-acetyl]-PAF and expressed as nmol/min $/ \mathrm{mg}$. (A) Box and Whisker plot showing median serum PAF-AH activity in wild-type mice during development. The levels of PAF-AH activity in adult mouse and human serum samples are shown for comparison. *represents $p<0.01$. (B) Gut PAF-AH activity in adult and neonatal wild-type (ם) and PAF-AH ${ }^{-1-}$ mice $(\square){ }^{*} p<0.0001$, age effect, ${ }^{* *} p<0.0001$, genotype effect.

A

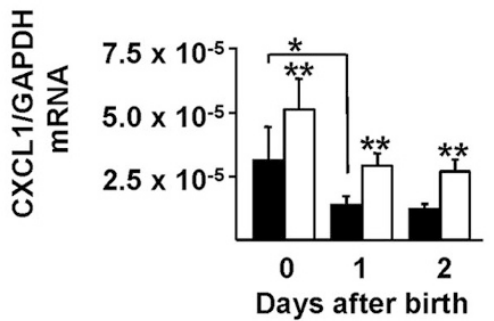

B

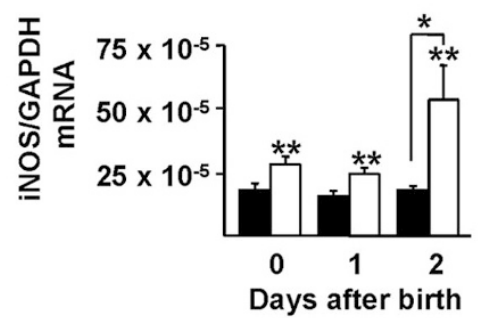

C

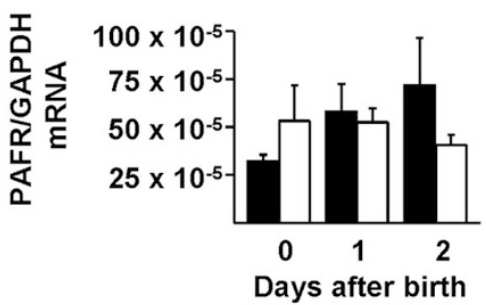

Figure 3. Expression of CXCL1 $(A)$, iNOS $(B)$, and PAFR $(C)$ mRNA in the ileum of wild-type and PAF-AH ${ }^{-1-}$ mice during development. mRNA levels were quantified by RT-PCR in the ileum of mother-fed wild-type (ם) and PAF-AH ${ }^{-1-}(\square)$ animals at 0,1 , and $2 \mathrm{~d}$ after birth. For CXCL1, * $p<0.01$, age effect and ${ }^{* *} p<0.01$, genotype effect. Two-day old pups displayed statistically higher iNOS levels compared with d 0 and $1\left({ }^{*} p<0.01\right)$. In contrast, we detected no genotype- or age-dependent differences in PAFR mRNA levels.

Developmental control of PAF-AH expression in mice. Human infants express low levels of circulating PAF-AH activity and expression levels progressively reach adult values by $6 \mathrm{wk}$ of life (9). We measured serum PAF-AH activity in pups of various ages and compared these values to those found in adult mouse serum samples. We found that neonatal and adult mice expressed comparable levels of PAF-AH activity in the plasma (Fig. 2A). All mice expressed higher levels of PAF-AH activity compared with humans (Fig. $2 A$ ), as previously reported (23).

Expression of PAF-AH in intestinal tissues. We next determined the levels of PAF-AH activity in intestinal tissues of neonatal and adult mice (Fig. $2 B$ ). We found that wild-type neonatal mice expressed higher intestinal PAF-AH activity compared with adult animals (Fig. 2B, two-way ANOVA, $p<$ 0.0001 , Bonferroni post hoc test). PAF-AH ${ }^{-/}$mice expressed significantly lower activity compared with wild-type animals, regardless of age (Fig. 2B, two-way ANOVA, $p<$ 0.0001 , Bonferroni post hoc test). The most robust differences in expression were observed by comparing neonatal PAF$\mathrm{AH}^{-1-}$ versus wild-type mice (Fig. $2 B$ ). These results confirm that deletion of the plasma form of PAF-AH abolishes expression of serum and intestinal activities.

Deletion of PAF-AH increases proinflammatory gene expression. We next sought to characterize the consequences of PAF-AH deletion on the expression of several key proin- flammatory mediators in healthy, mother-fed neonatal mice. We measured CXCL1 and inducible NOS (iNOS) mRNA expression because these mediators regulate key pathways in intestinal inflammation $(24,25)$ and repair $(26)$. In addition, we evaluated PAFR mRNA levels because this receptor regulates PAF-induced signaling. We found that PAF-AH ${ }^{-1-}$ pups expressed higher levels of CXCL1 compared with wild-type controls (Fig. 3A). In addition, we observed that CXCL1 expression decreased with age in mice of both genotypes (Fig. $3 A, p<0.05$; two-way ANOVA). Deletion of PAF-AH also resulted in higher intestinal iNOS expression (Fig. $3 B, p<$ 0.01 , two-way ANOVA). Although the levels of iNOS remained constant in wild-type mice over the period studied, iNOS expression increased significantly by $2 \mathrm{~d}$ of life in PAF-AH ${ }^{-\prime-}$ animals compared with wild-type controls (Fig. $3 B$ ). In contrast, PAFR expression was similar between wildtype and knockout mice (Fig. 3C).

Survival of wild-type and $\mathrm{PAF}-\mathrm{AH} \mathrm{H}^{-/-}$mice after bacterial challenge. To evaluate whether deletion of PAF-AH affected survival and/or NEC incidence, we used our model of NEC that includes asphyxia, formula feeding, and bacterial supplementation (16). When we subjected C57BL/6J wild-type and PAF-AH knockout mice to our model of NEC, we observed high early mortality rates in wild-type cohorts and lower incidence of early death in the PAF-AH knockout strain (Fig. 4). The etiology of early death was initially unclear, but 


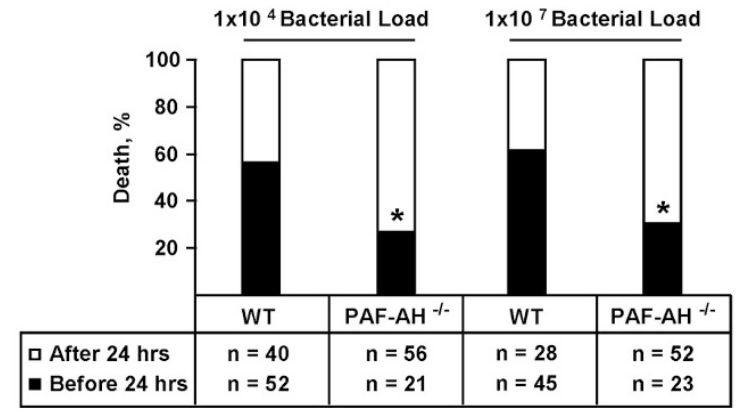

Figure 4. Mortality rates of wild-type and PAF-AH ${ }^{-1-}$ mice before and after $24 \mathrm{~h}$ of life. Pups retrieved from timed-pregnant wild-type and PAF$\mathrm{AH}^{-1-}$ mice by cesarean section between E20 and E21 were subjected to our NEC protocol using a $1 \times 10^{4}$ or $1 \times 10^{7}$ bacterial load of Serratia marcescens and Streptococcus viridans in their first feeding after birth and on each succeeding day. Mortality incidence was significantly higher in wildtype compared with PAF-AH ${ }^{-1-}$ mice before $24 \mathrm{~h}$ of life (Fisher's exact test, $* p<0.001)$.

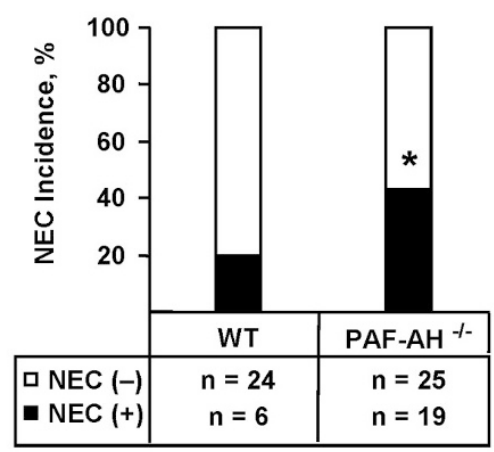

Figure 5. NEC incidence in wild-type and PAF-AH ${ }^{-1-}$ mice after $24 \mathrm{~h}$ of life. Intestinal samples were scored on a scale of $0-4$ to evaluate NEC severity. Animals that survived longer than $24 \mathrm{~h}$ with a score $\geq 2$ were considered to have NEC. Data were analyzed using a $\chi^{2}$ test. The incidence of NEC in PAF-AH ${ }^{-1-}$ pups $(43 \%)$ was significantly higher than that observed in wild-type controls $(20 \%, * p<0.05)$. further studies revealed the presence of Serratia marscesens and Streptococcal viridans in the bloodstream of a high percentage of animals. To reduce the risk for sepsis and early death associated with exogenous bacterial supplementation, we lowered the bacterial load to $1 \times 10^{4}$ organisms/animal/d. However, this alteration did not significantly decrease the death rate (Fig. 4). Thus, deletion of PAF-AH decreased the incidence of early death after bacterial supplementation (Fisher's exact test, $p<0.001)$. These results suggest that accumulation of PAF and perhaps other PAF-AH substrates is protective against neonatal bacterial infection.

Susceptibility of wild-type and PAF-AH ${ }^{-/}$mice to $\mathrm{NEC}$. We next compared the incidence of NEC in wild-type and PAF- $\mathrm{AH}^{-1-}$ animals that survived after $24 \mathrm{~h}$. In these studies, we used a bacterial load of $1 \times 10^{4}$ organisms/animal/d and found higher incidence of NEC in PAF-AH ${ }^{-/}$animals (43\%, 19 NEC-positive versus 25 NEC-negative animals) compared with wild-type pups (20\%, 6 NEC positive versus 24 NECnegative animals, $\chi^{2}$ test, $p<0.05$ ) (Fig. 5). Similar to our previous studies, the severity of histologic injury was quite variable in both wild-type and PAF-AH ${ }^{-1-}$ animals, and anatomic location was most prominent in ileum and proximal colon.

Proinflammatory gene expression in cold- and asphyxiastressed wild-type and PAF-AH ${ }^{-/-}$mice. We found that PAF-AH ${ }^{-1-}$ pups expressed significantly higher levels of CXCL1 and iNOS compared with wild-type animals (Fig. 6, A and $B, p<0.05$; unpaired $t$ test with Welch's correction). These differences were observed regardless of whether the animals died before or after $24 \mathrm{~h}$ of life (Fig. 6, $A$ and $B$ ) and surpassed the increases in expression observed between healthy, mother-fed, wild-type and PAF-AH ${ }^{-1-}$ mice (Fig. 3). We detected no differences in ileal PAFR mRNA levels in wild-type versus $\mathrm{PAF}-\mathrm{AH}^{-1-}$ pups subjected to our NEC model (Fig. 6C), suggesting that the capacity for PAFRmediated signaling was not affected by deletion of PAF-AH. To investigate whether the potential for PAF production was differentially affected in wild-type and PAF-AH ${ }^{-1-}$ pups, we assessed the levels of ileal sPLA $\mathrm{P}_{2}$ in both cohorts. We found that PAF-AH deficient mice subjected to our NEC model
A

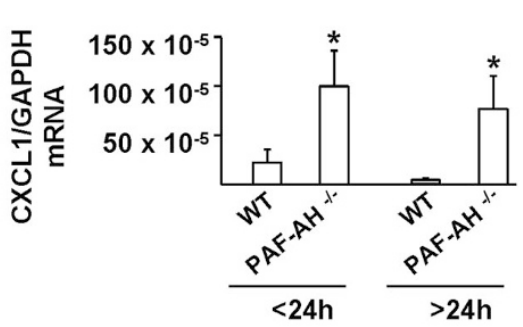

C

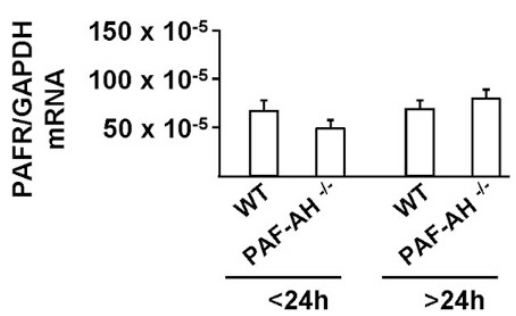

B
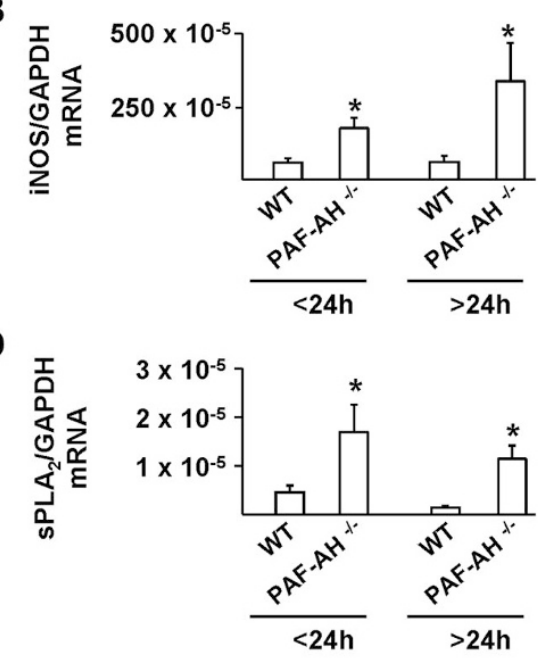

Figure 6. Expression of CXCL1 $(A)$, iNOS $(B)$, PAFR $(C)$, and $\operatorname{sPLA}_{2}(D)$ mRNA in mice subjected to a model of NEC. mRNA levels were quantified by RT-PCR in the ileum of wild-type and PAF-AH ${ }^{-1-}$ mice subjected to our model of NEC using $1 \times 10^{4}$ bacterial load of Serratia marcescens and Streptococcus viridans. PAF-AH ${ }^{-1-}$ expressed higher levels of mRNA for CXCL1 $(* p<0.05 ; t$ test), iNOS (*p<0 $0.05 ; t$ test), and $\mathrm{sPLA}_{2}$ $\left({ }^{*} p<0.05 ; t\right.$ test $)$. In contrast, we detected no genotype- or time-of-death-dependent differences in PAFR expression. 
expressed elevated levels of $\mathrm{sPLA}_{2}$ mRNA compared with equally treated wild-type animals, and that the extent of up-regulation varied according to survival. $\mathrm{PAF}-\mathrm{AH}^{-/-}$animals that perished before $24 \mathrm{~h}$ displayed 3.7-fold higher levels of $\mathrm{SPLA}_{2}$ mRNA compared with wild-type controls (Fig. 6D). PAF-AH ${ }^{-1-}$ pups that survived longer than $24 \mathrm{~h}$ displayed 8-fold higher ileal sPLA ${ }_{2}$ compared with wild-type pups ( $p<$ 0.05 ; unpaired $t$ test with Welch's correction, Fig. 6D). Increased expression of one of the rate-limiting enzymes in the PAF biosynthetic pathway suggests the possibility that a positive feedback loop leading to additional PAF synthesis is operative in $\mathrm{PAF}-\mathrm{AH}^{-/-}$pups.

\section{DISCUSSION}

In this study, we demonstrate that neonatal mice deficient in endogenous PAF-AH are more susceptible to NEC in response to formula feeding, bacterial colonization, and asphyxia/ cold stress, compared with wild-type pups. Because neonatal human infants have very low endogenous PAF-AH activity, this new model provides significant insight into the pathophysiology of neonatal NEC. PAF-AH ${ }^{-/-}$mice exposed to the NEC protocol expressed significantly higher $\mathrm{SPLA}_{2}$, CXCL1, and iNOS compared with wild-type animals. These findings suggest that PAF-AH deficiency increases $\mathrm{SPLA}_{2}$ and subsequent PAF accumulation, resulting in robust upregulation of proinflammatory gene expression, intestinal inflammation, and NEC.

Several studies have investigated the importance of PAF and PAF-AH in the pathogenesis of NEC. In animal models, intra-aortic injection of PAF into adult rats caused ischemic intestinal necrosis similar to that observed in patients with NEC (27); pretreatment with dexamethasone or medroxyprogesterone significantly increased plasma PAF-AH activity and prevented the gross and histologic features of NEC (28). These observations support a role for endogenous PAF and PAF-AH activity as opposite players in the control of acute intestinal necrosis. We previously developed a neonatal rat model of NEC that incorporates key features of the human disease, including asphyxia, formula feeding, and bacterial colonization (14). In this model, enteral administration of recombinant $\mathrm{PAF}-\mathrm{AH}$ significantly reduced the incidence of NEC (14). Our observation that neonatal rodents express high levels of endogenous plasma and intestinal PAF-AH activity (this study) while neonatal humans are deficient (9), led us to hypothesize that neonatal mice deficient in the endogenous enzyme might be a better model of human NEC. This study demonstrates that deficiency of intestinal and circulating PAF-AH markedly increases the severity of inflammation and the incidence of NEC, and due to adequate PAF-degrading capacity, wild-type control mice may not be a reliable model for human, neonatal disease.

We previously demonstrated a significant role for PAFinduced intestinal injury in experimental NEC (2,5). The mechanism whereby deletion of PAF-AH increases NEC severity is likely to involve exacerbated PAF signaling. PAF homeostasis is defined at the biosynthetic and catabolic levels (4). PAF biosynthesis through the remodeling pathway re- quires participation of specific $\mathrm{PLA}_{2}$ isoforms and recently described lyso-PAF acetyltransferases $(29,30)$. PAF-AH activities down-regulate PAF signaling in several biologic compartments. The observation that human neonates are deficient in circulating PAF-AH activity, combined with the presence of active enzyme in breast milk, led to the hypothesis that milk PAF-AH may confer protection against NEC development in preterm newborns (13). Recent work by Chen et al. (31) showed that inhibition of PAF-AH induces PAF accumulation equivalent to that observed after agonist stimulation in quiescent neutrophils and monocytes. These combined observations point to increased PAF signaling as a feature associated with PAF-AH deletion. The functional consequences associated with exacerbated PAF signaling in the intestine remain to be completely characterized, but previous work demonstrated that PAF up-regulates expression of sPLA $_{2}$ in this organ (32). In this study, we found that deletion of PAF-AH was associated with higher levels of ileal $\mathrm{sPLA}_{2}$ mRNA in pups challenged with our NEC protocol. Thus, a feed forward mechanism of increased $\mathrm{SPLA}_{2}$ and subsequent PAF production may account for enhanced NEC severity in PAF$\mathrm{AH}^{-1-}$ neonatal mice.

Increased inflammation is a feature of neonatal NEC in humans and in animal models of the disease (33-35). The proinflammatory functions of PAF suggest key roles in the final common pathway leading to NEC (2). We found that deficiency of PAF-AH was associated with increased levels of iNOS and CXCL1 (IL-8 in humans), two mediators whose expression has been shown to contribute to intestinal inflammation $(36,37)$. Interestingly, the expression of these proinflammatory genes was elevated in unstressed, PAF-AH deficient animals. However, stress from bacterial exposure, formula feeding, and asphyxia further increased CXCL1 and iNOS mRNA levels in PAF-AH ${ }^{-1-}$ pups compared with wild-type animals. These observations underscore that endogenous PAF-AH has important anti-inflammatory functions in neonatal animals.

Our studies revealed interesting and unexpected findings related to the role of endogenous PAF-AH in the intestine. We found that early mortality was lower (20-30\%) in PAF-AH knockout compared with wild-type mice, regardless of bacterial load. Our ability to observe these differences was likely facilitated by the unexpected finding that the C57BL/6J background conferred neonatal mice with exquisite sensitivity to bacterial exposure. Blood culture results from these animals confirmed that most pups died from septic shock. The observation that $\mathrm{PAF}-\mathrm{AH}^{-/-}$animals survived significantly longer than wild-type pups when subjected to identical stress suggests that increased local and systemic PAF and/or other PAF-AH substrates may be protective. PAF has been shown to be required for the ability of neutrophils to kill bacteria (38), and this property may attenuate early bacterial translocation, thus limiting events that lead to septic shock in newborns. Our combined results are consistent with a model whereby suboptimal PAF levels predispose an organism to infection, whereas excessive production of the mediator contributes to inflammation and bowel necrosis.

In conclusion, we have demonstrated that genetically deficient PAF-AH mice are protected from early mortality in 
response to bacterial exposure, formula feeding, and asphyxia but develop significantly more NEC after $24 \mathrm{~h}$ compared with wild-type controls. The incidence of NEC correlates with increased intestinal proinflammatory gene expression in PAF-AH knockout animals. These novel findings identify two different roles for PAF-AH in the regulation of key responses during neonatal development. Our results highlight the potential utility of exogenous PAF-AH supplementation for the prevention of NEC in premature infants.

Acknowledgments. We are indebted to Liping Chen for key contributions to the development of PAF-AH-deficient mice before her untimely death. We are indebted to Katrina A. Lund, Ethan C. Reichert, and Alison A. Gardner (University of Utah) for excellent technical assistance. We also thank Drs. Michaeline Bunting, Stephen M. Prescott, Kenneth W. Spitzer, Kirk Thomas, and Matthew K. Topham for valuable advice and discussions.

\section{REFERENCES}

1. Henry MC, Moss RL 2009 Necrotizing enterocolitis. Annu Rev Med 60:111-124

2. Caplan MS, MacKendrick W 1994 Inflammatory mediators and intestinal injury. Clin Perinatol 21:235-246

3. Caplan MS, Hedlund E, Adler L, Hsueh W 1994 Role of asphyxia and feeding in a neonatal rat model of necrotizing enterocolitis. Pediatr Pathol 14:1017-1028

4. Prescott SM, Zimmerman GA, Stafforini DM, McIntyre TM 2000 Platelet-activating factor and related lipid mediators. Annu Rev Biochem 69:419-445

5. Caplan MS, Kelly A, Hsueh W 1992 Endotoxin and hypoxia-induced intestinal necrosis in rats: the role of platelet activating factor. Pediatr Res 31:428-434

6. Hsueh W, Caplan MS, Sun X, Tan X, MacKendrick W, Gonzalez-Crussi F 1994 Platelet-activating factor, tumor necrosis factor, hypoxia and necrotizing enterocolitis. Acta Paediatr Suppl 396:11-17

7. Sun X, Caplan MS, Hsueh W 1994 Tumour necrosis factor and endotoxin synergistically activate intestinal phospholipase $\mathrm{A}_{2}$ in mice. Role of endogenous platelet activating factor and effect of exogenous platelet activating factor. Gut 35:215-219

8. Caplan MS, Hsueh W, Sun XM, Gidding SS, Hageman JR 1990 Circulating plasma platelet activating factor in persistent pulmonary hypertension of the newborn. Am Rev Respir Dis 142:1258-1262

9. Caplan M, Hsueh W, Kelly A, Donovan M 1990 Serum PAF acetylhydrolase increases during neonatal maturation. Prostaglandins 39:705-714

10. Stafforini DM 2009 Biology of platelet-activating factor acetylhydrolase (PAF-AH, lipoprotein associated phospholipase $\mathrm{A}_{2}$ ). Cardiovasc Drugs Ther 23:73-83

11. Stafforini DM, McIntyre TM, Carter ME, Prescott SM 1987 Human plasma plateletactivating factor acetylhydrolase. Association with lipoprotein particles and role in the degradation of platelet-activating factor. J Biol Chem 262:4215-4222

12. Arai H 2002 Platelet-activating factor acetylhydrolase. Prostaglandins Other Lipid Mediat 68-69:83-94

13. Moya FR, Eguchi H, Zhao B, Furukawa M, Sfeir J, Osorio M, Ogawa Y, Johnston JM 1994 Platelet-activating factor acetylhydrolase in term and preterm human milk: a preliminary report. J Pediatr Gastroenterol Nutr 19:236-239

14. Caplan MS, Lickerman M, Adler L, Dietsch GN, Yu A 1997 The role of recombinant platelet-activating factor acetylhydrolase in a neonatal rat model of necrotizing enterocolitis. Pediatr Res 42:779-783

15. Caplan MS, Jilling T 2001 The role of polyunsaturated fatty acid supplementation in intestinal inflammation and neonatal necrotizing enterocolitis. Lipids 36:1053-1057

16. Jilling T, Simon D, Lu J, Meng FJ, Li D, Schy R, Thomson RB, Soliman A, Arditi M, Caplan MS 2006 The roles of bacteria and TLR4 in rat and murine models of necrotizing enterocolitis. J Immunol 177:3273-3282

17. Jilling T, Lu J, Jackson M, Caplan MS 2004 Intestinal epithelial apoptosis initiates gross bowel necrosis in an experimental rat model of neonatal necrotizing enterocolitis. Pediatr Res 55:622-629
18. Narahara H, Frenkel RA, Johnston JM 1993 Secretion of platelet-activating factor acetylhydrolase following phorbol ester-stimulated differentiation of HL-60 cells. Arch Biochem Biophys 301:275-281

19. Miwa M, Miyake T, Yamanaka T, Sugatani J, Suzuki Y, Sakata S, Araki Y, Matsumoto M 1988 Characterization of serum platelet-activating factor (PAF) acetylhydrolase. Correlation between deficiency of serum PAF acetylhydrolase and respiratory symptoms in asthmatic children. J Clin Invest 82:1983-1991

20. Stafforini DM, McIntyre TM, Prescott SM 1990 Platelet-activating factor acetylhydrolase from human plasma. Methods Enzymol 187:344-357

21. Caplan MS, Russell T, Xiao Y, Amer M, Kaup S, Jilling T 2001 Effect of polyunsaturated fatty acid (PUFA) supplementation on intestinal inflammation and necrotizing enterocolitis (NEC) in a neonatal rat model. Pediatr Res 49:647-652

22. Bunting M, Bernstein KE, Greer JM, Capecchi MR, Thomas KR 1999 Targeting genes for self-excision in the germ line. Genes Dev 13:1524-1528

23. Gardner AA, Reichert EC, Topham MK, Stafforini DM 2008 Identification of a domain that mediates association of platelet-activating factor acetylhydrolase with high density lipoprotein. J Biol Chem 283:17099-17106

24. Heuvelin E, Lebreton C, Grangette C, Pot B, Cerf-Bensussan N, Heyman M 2009 Mechanisms involved in alleviation of intestinal inflammation by bifidobacterium breve soluble factors. PLoS One 4:e5184

25. Singer II, Kawka DW, Scott S, Weidner JR, Mumford RA, Riehl TE, Stenson WF 1996 Expression of inducible nitric oxide synthase and nitrotyrosine in colonic epithelium in inflammatory bowel disease. Gastroenterology 111:871-885

26. Bove PF, Wesley UV, Greul AK, Hristova M, Dostmann WR, van der Vliet A 2007 Nitric oxide promotes airway epithelial wound repair through enhanced activation of MMP-9. Am J Respir Cell Mol Biol 36:138-146

27. Gonzalez-Crussi F, Hsueh W 1983 Experimental model of ischemic bowel necrosis. The role of platelet-activating factor and endotoxin. Am J Pathol 112:127-135

28. Furukawa M, Lee EL, Johnston JM 1993 Platelet-activating factor-induced ischemic bowel necrosis: the effect of platelet-activating factor acetylhydrolase. Pediatr Res 34:237-241

29. Shimizu T 2009 Lipid mediators in health and disease: enzymes and receptors as therapeutic targets for the regulation of immunity and inflammation. Annu Rev Pharmacol Toxicol 49:123-150

30. Shindou H, Hishikawa D, Nakanishi H, Harayama T, Ishii S, Taguchi R, Shimizu T 2007 A single enzyme catalyzes both platelet-activating factor production and membrane biogenesis of inflammatory cells. Cloning and characterization of acetylCoA:LYSO-PAF acetyltransferase. J Biol Chem 282:6532-6539

31. Chen J, Yang L, Foulks JM, Weyrich AS, Marathe GK, McIntyre TM 2007 Intracellular PAF catabolism by PAF acetylhydrolase counteracts continual PAF synthesis. J Lipid Res 48:2365-2376

32. Tan XD, Wang H, Gonzalez-Crussi FX, Chang H, Gonzalez-Crussi F, Hsueh W 1996 Platelet activating factor and endotoxin increase the enzyme activity and gene expression of type II phospholipase $\mathrm{A}_{2}$ in the rat intestine. Role of polymorphonuclear leukocytes. J Immunol 156:2985-2990

33. Caplan MS, Hedlund E, Hill N, MacKendrick W 1994 The role of endogenous nitric oxide and platelet-activating factor in hypoxia-induced intestinal injury in rats. Gastroenterology 106:346-352

34. De Plaen IG, Liu SX, Tian R, Neequaye I, May MJ, Han XB, Hsueh W, Jilling T, Lu J, Caplan MS 2007 Inhibition of nuclear factor-kappaB ameliorates bowel injury and prolongs survival in a neonatal rat model of necrotizing enterocolitis. Pediatr Res 61:716-721

35. Caplan MS, Sun XM, Hseuh W, Hageman JR 1990 Role of platelet activating factor and tumor necrosis factor-alpha in neonatal necrotizing enterocolitis. J Pediatr 116:960-964

36. Nadler EP, Dickinson E, Knisely A, Zhang XR, Boyle P, Beer-Stolz D, Watkins SC, Ford HR 2000 Expression of inducible nitric oxide synthase and interleukin-12 in experimental necrotizing enterocolitis. J Surg Res 92:71-77

37. Nadler EP, Stanford A, Zhang XR, Schall LC, Alber SM, Watkins SC, Ford HR 2001 Intestinal cytokine gene expression in infants with acute necrotizing enterocolitis: interleukin-11 mRNA expression inversely correlates with extent of disease. J Pediatr Surg 36:1122-1129

38. Rubin BB, Downey GP, Koh A, Degousee N, Ghomashchi F, Nallan L, Stefanski E, Harkin DW, Sun C, Smart BP, Lindsay TF, Cherepanov V, Vachon E, Kelvin D, Sadilek M, Brown GE, Yaffe MB, Plumb J, Grinstein S, Glogauer M, Gelb MH 2005 Cytosolic phospholipase $\mathrm{A}_{2}$-alpha is necessary for platelet-activating factor biosynthesis, efficient neutrophil-mediated bacterial killing, and the innate immune response to pulmonary infection: cPLA2-alpha does not regulate neutrophil NADPH oxidase activity. J Biol Chem 280:7519-7529 